\title{
Withdrawal Symptoms in Workers Exposed to Nitroglycerine
}

\author{
R. P. LUND, J. HÄGGENDAL, and G. JOHNSSON \\ From AB Bofors Nobelkrut, Bofors, and the Department of Pharmacology, University of Göteborg, Sweden
}

Several reports during the last few years have described chest pain and sudden death in workers exposed to nitroglycol or nitroglycol in combination with nitroglycerine. A report is given here of nine persons suffering from chest pain (including one sudden death) after exposure to nitroglycerine alone. The pains occurred between 30 and 65 hours after termination of the exposure. The differential diagnosis from angina pectoris is discussed.

It has long been known that disorders occur among workers handling nitroglycerine and nitroglycol. Thus, during exposure to nitroglycerinenitroglycol immediate reactions such as headaches, nausea, dizziness, heart palpitations, sweating, tiredness, and diffuse pains may occur (Forssman, Masreliez, Johansson, Sundell, Wilander, and Boström, I958; Munch and Friedland, I965; Trainor and Jones, 1966). In some cases, the incapacity may be so severe that exposure must be terminated. When these effects are less severe a tolerance is established within a week (Melville, 1965). Thereafter the symptoms generally disappear or become rather mild. When the exposure is interrupted for a short period of time, e.g., for about a day, no significant reduction in tolerance is noted. After a longer period of absence, however, the symptoms reappear on subsequent re-exposure to the agent.

Since 1952, several reports (Symanski, 1952; Barsotti, 1954; Yamaguchi, Sakabe, Kajita, Yoshikawa, Hashizume, Matsushita, and Matsumura, 1960; Sakoda, 1962; Bille and Sivertssen, 1963; Carmichael and Lieben, 1963) have been concerned with another type of reaction after exposure to nitroglycol or nitroglycol with nitroglycerine. After continuous exposure to these agents for a number of years, an interruption of the exposure may be followed by pains in the chest. This symptom generally appears within 24 to 72 hours after the interruption of the exposure. The pains resemble attacks of angina pectoris but do not occur in relation to exercise or emotional stimuli. The pains often disappear shortly after the exposure starts again. Sometimes the attacks of pain may result in death.
At necropsy often no significant signs of atherosclerotic changes in the heart have been observed. The symptoms of this condition are hereinafter referred to as 'withdrawal symptoms'.

The cases with withdrawal symptoms reported so far have occurred after exposure to nitroglycol or to a mixture of nitroglycol and nitroglycerine (Symanski, 1952; Barsotti, I954; Yamaguchi et al., 1960; Sakoda, 1962; Bille and Sivertssen, 1963; Carmichael and Lieben, 1963). There has been a tendency to ascribe the symptoms predominantly to the effect of nitroglycol (Barsotti, 1954). Therefore nine cases of attacks of sternocardiac pains, including one death, among nitroglycerine workers appear to be of special interest. The cases were observed during the last eight years at a Swedish explosives factory, when the workers were directly handling the nitroglycerine. Although they wore protective clothing and gloves, some absorption might have occurred through the skin.

\section{Case Reports}

The cases are summarized in the Table.

Case I A 35-year-old man had been exposed to nitroglycerine for nine years. He died on the morning of 2 May 1959 as a result of a heart attack resembling infarctus cordis. He had ceased work on April $30^{1}$ at 12.30 p.m.

In December 1958 he had consulted the industrial physician about severe attacks of chest pain resembling angina pectoris. The pains used to occur on Sundays, either in the evening or in the night. Very soon after he had returned to work on Mondays the pains disappeared. The examination in December 1958 revealed nothing pathological, a normal electrocardiogram (E.C.G.) and

\footnotetext{
${ }^{1}$ In Sweden, May I is a public holiday.
} 
TABLE

CASES OF Nitroglycerine WithDRAWAL SyMPTOMS, 1959-66

\begin{tabular}{|c|c|c|c|c|c|c|}
\hline No. & Sex & Age & $\begin{array}{c}\text { Exposure } \\
(y r s)\end{array}$ & Attacks & $\begin{array}{l}\text { Interval between } \\
\text { Last Exposure } \\
\text { and Onset of } \\
\text { Symptoms (hrs) }\end{array}$ & Comments \\
\hline $\begin{array}{l}\text { I } \\
2 \\
3 \\
4 \\
5\end{array}$ & $\begin{array}{l}\mathbf{M} \\
\mathbf{M} \\
\mathbf{M} \\
\mathbf{M}\end{array}$ & $\begin{array}{l}35 \\
50 \\
44 \\
55 \\
38\end{array}$ & $\begin{array}{r}9 \\
27 \\
12 \\
21 \\
10\end{array}$ & $\begin{array}{l}\text { Several, increasing in severity } \\
\text { Six, moderate } \\
\text { Several, moderate } \\
\text { Several, moderate } \\
\text { Two, light to moderate }\end{array}$ & $\begin{array}{l}34-46 \\
\text { Approx. 50 } \\
30-62 \\
30-62 \\
40-48\end{array}$ & $\begin{array}{l}\text { Died } \\
\text { Recovered } \\
\text { Recovered } \\
\text { Recovered } \\
\text { Recovered }\end{array}$ \\
\hline $\begin{array}{l}6 \\
7 \\
8 \\
9\end{array}$ & $\begin{array}{l}\mathrm{M} \\
\mathrm{F} \\
\mathrm{M} \\
\mathrm{M}\end{array}$ & $\begin{array}{l}51 \\
45 \\
48 \\
50\end{array}$ & $\begin{array}{r}13 \\
11 \\
2 \\
7\end{array}$ & $\begin{array}{l}\text { Several, moderate } \\
\text { Five, increasing } \\
\text { Two light, one severe } \\
\text { Three, light }\end{array}$ & $\begin{array}{l}\text { Approx. } 55 \\
53-62 \\
38-60 \\
53-65\end{array}$ & $\begin{array}{l}\text { Recovered } \\
\text { Recovered } \\
\text { Recovered } \\
\text { Recovered }\end{array}$ \\
\hline
\end{tabular}

a blood pressure of $130 / 80 \mathrm{~mm}$. $\mathrm{Hg}$.

The man was given isonitol-nicotinate to be taken as a prophylactic on Sundays. At a routine examination in January 1959 he stated that the disorders had not recurred after he started to take the drug. After his death it was revealed that, in fact, the attacks of chest pains had returned, but he did not visit the physician. The necropsy revealed nothing pathological except congestion of the lungs.

Case 2 A 50-year-old man had been exposed to nitroglycerine for about 27 years. His previous health had been good but he had suffered from a mild headache when returning to work after holidays.

In 1959 he had two attacks of pain localized to the chest and along the right arm. In 1960 and 1961 there were four further attacks of the same type, always at 2 to 3 o'clock on a Monday morning, lasting one to two hours. The pain was relieved by walking around. During the course of an attack he was examined at a hospital, but no abnormality was found clinically or in the E.C.G. Nitroglycerine reduced the pains.

He was removed from exposure to nitroglycerine in I96I and has had no further heart trouble.

Case 3 A 44-year-old man had been exposed to nitroglycerine for about 12 years. During this time the patient had sometimes suffered from mild headaches and liquid stools. Since 1959 he had had several attacks of pain in the chest, lasting ro to 20 minutes and occurring mainly in the mornings. The attacks were not restricted to the week-ends. Examinations at hospital and by the industrial physician did not reveal any clinical abnormality.

He was removed from exposure to nitroglycerine in 1961. Since then the heart trouble has not reappeared. The man is an active sportsman (football player).

Case 4 A 55-year-old man had been exposed to nitroglycerine on and off for about 21 years. Since 1960 he had, on Sundays or free Saturdays, and once on a
Monday morning, suffered from several attacks of a feeling of cramp in the chest. The symptoms generally lasted about 30 minutes. On examination a systolic blowing sound was found over the apex; otherwise there was no abnormality. The blood pressure was 125/80 $\mathrm{mm}$. $\mathrm{Hg}$ and the E.C.G. was normal.

There has been no recurrence of symptoms since exposure to nitroglycerine ceased in 1961 .

Case 5 A 38-year-old-man had been exposed to nitroglycerine for to years. $\mathrm{He}$ had suffered from occasional headaches due to nitroglycerine exposure. In 196I he had two short attacks of pain in the chest on the second day when absent from work. There was nothing abnormal found either clinically or in the E.C.G. The blood pressure was $120 / 85 \mathrm{~mm}$. $\mathrm{Hg}$.

There were no attacks of chest pain after exposure to nitroglycerine was stopped in 196I. After one year the worker left the company, and since then he has not been observed.

Case 6 A 51-year-old man had been exposed to nitroglycerine for 13 years. In 1952 he had a partial gastrectomy because of a gastric ulcer. He complained of headaches after absence from work but was otherwise healthy. In the spring of 1965 he had several attacks of chest pain lasting 20 to 25 minutes. During this period he did not work on Sundays. In the summer, on one occasion during a Sunday night, he had three attacks of chest pain. Nothing abnormal was revealed on examination four days later; the blood pressure was $145 / 80$ $\mathrm{mm}$. $\mathrm{Hg}$.

Nitroglycerine was prescribed to be taken the following week-end, and the pain ceased. No further attacks occurred.

Case 7 A 45-year-old woman had been exposed to nitroglycerine for I I years. She suffered from headache, usually on Mondays, and for several years had had myalgia in the neck and shoulders.

In 1965 this patient started a new type of work in 
which there was a higher degree of nitroglycerine exposure. Thereafter, on three Monday mornings she had attacks of pain in the chest, together with a constrictive feeling in the throat. These attacks of pain lasted for 15 minutes and ceased after she returned to work. The industrial physician found nothing abnormal on examination. The blood pressure was $125 / 80 \mathrm{~mm}$. $\mathrm{Hg}$ and the E.C.G. was normal. No further symptoms occurred after exposure was stopped in 1965.

Case 8 A 48-year-old man had been exposed to nitroglycerine for two years. He was exposed to diethylene-glycol-di-nitrate for 24 hours during one week-end in 1965. During the rest of the week he worked with nitroglycerine. He had no exposure the following Saturday, but on the Sunday he experienced three attacks of numbness in the shoulders and arms; each attack lasted for about 15 minutes. Early on Monday morning, the patient had an attack of severe chest pain, radiating into both arms, and he was admitted to hospital. On admission he was weak and sweating but had no pain. Nothing abnormal was found clinically or in the E.C.G. The blood pressure was $120 / 80 \mathrm{~mm}$. Hg. The excretion of noradrenaline and adrenaline in the urine was within normal values when the patient was free from pain. After returning to work in a nitroglycerine-free milieu in autumn 1965, he has had no further attacks of pain.

Case 9 A 50-year-old man had been exposed to nitroglycerine for seven years on and off since 195 I. In 1952 he had a gastric ulcer. He was otherwise healthy and did not suffer from headaches. After the summer vacation of 1966 he had slight headaches. Two days after exposure to nitroglycerine in 1966 he suffered from chest pains lasting ro minutes. The next week-end there were two further attacks of pain. He was examined at the local hospital immediately after the last attack, but nothing abnormal was found. Since the exposure to nitroglycerine was discontinued there have been no further attacks.

\section{Comments}

There are now so many reports on cases of withdrawal symptoms and sudden death among persons handling nitroglycerine-nitroglycol that the connexion between the symptoms and the exposure may be regarded as confirmed. Previously, the withdrawal symptoms have been ascribed to exposure either to nitroglycol or to a combination of nitroglycol and nitroglycerine.

The withdrawal symptoms in the present cases, following nitroglycerine exposure, appear to be the same as those ascribed to nitroglycol exposure (Symanski, r952; Barsotti, 1954; Yamaguchi et al., 1960; Sakoda, 1962). Thus the most obvious symptom is the pain resembling that of angina pectoris. This pain starts as a rule one to three days after interruption of exposure to nitroglycerine, as it does after interruption of exposure to nitroglycol.
It is important to distinguish this pain from the pain of angina pectoris due to atherosclerosis. The 35year-old patient who died of an attack resembling cardiac infarction had, at necropsy, no signs of atherosclerotic changes in the coronary arteries. None of the cases reported here had any evidence of true angina pectoris clinically or on the E.C.G. Furthermore, when working later in a nitroglycerine-free milieu, these workers have not suffered from any attacks of chest pain. Five of them have now been observed for five years or longer in their new working milieu, which is often physically demanding.

Qualitatively, nitroglycol and nitroglycerine thus appear to induce the same withdrawal reactions in workers. Withdrawal symptoms after exposure to nitroglycol seem to be more frequent than after exposure to nitroglycerine alone. This may be explained partially by lower toxicity (cf. Gross, Bock, and Hellrung, I942; Forssman et al., 1958) and by the fact that the vapour pressure of nitroglycerine is lower than that of nitroglycol. The mechanism responsible for withdrawal symptoms has not been clarified. There were no findings in the necropsy which could explain the sudden death.

The study was supported by the Swedish Medical Research Council (B67-14X-166-03 and B68-14X-16604 ) and by Läkemedelsindustriföreningen, Stockholm.

\section{REFERENCES}

Barsotti, M. (1954). Attacchi stenocardici nei lavoratori addetti alla produzione delle dinamite con nitroglicole. Med. d. Lavoro, 45, 544-548.

Bille, S., and Sivertssen, E. (1963). Nitroglycerin og nitroglykol som yrkesmedisinsk problem. Nord. Med., 70, 837-84I.

Carmichael, P., and Lieben, J. (1963). Sudden death in explosives workers. Arch. environm. Hlth, 7, 424-439.

Forssman, S., Masreliez, N., Johansson, G., Sundell, G., Wilander, O., and Boström, G, (1958). Untersuchungen des Gesundheitszustandes von Nitroarbeitern bei drei schwedischer Sprengstoffabriken. Arch. Gewerbepath. Gewerbehyg., 16, $157-177$.

Gross, E., Bock, M., and Hellrung, F. (1942). Zur Toxikologie des Nitroglykols im Vergleich zu der des Nitroglycerins. Naunyn-Schmiedebergs' Arch. exp. Path. Pharmakol., 200, 271-304.

Melville, K. I. (1965). Coronary vasodilators. In Drill's Pharmacology in Medicine. 3rd. ed. Ed. Di Palma, J. R., pp. 594-623. McGraw-Hill, New York.

Munch, J. C., and Friedland, B. (1965). Glyceryl trinitrate. I. Acute toxicity. Industr. Med. Surg., 34, 143-146.

Sakoda, A. (1962). A clinical study on nitroglycol poisoning. fap. F. industr. Hlth, 4, 583 .

Symanski, H. (1952). Schwere Gesundheitsschädigungen durch berufliche Nitroglykoleinwirkung. Arch. Hyg. (Berl.), 136, 139-1 58.

Trainor, D. C., and Jones, R. C. (I966). Headaches in explosive magazine workers. Arch. environm. Hlth, 12, 23I-234.

Yamaguchi, M., Sakabe, H., Kajita, A., Yoshikawa, H., Hashizume, M., Matsushita, H., and Matsumura, Y. (1960). Nitroglycol poisoning in an explosives plant. Bull. nat. Inst. industr. Hlth, 4, 54-71. 